\title{
El rastreo de la infección por el virus de la inmunodeficiencia humana en individuos asintomáticos sin antecedentes de riesgo
}

Screening human immunodeficiency virus infection in asymptomatic individuals with no history of risk

Natividad Burdiso , Sergio Terrasa y Karin Kopitowski

\begin{abstract}
Resumen
Este artículo resume la evolución histórica de las recomendaciones de rastreo de la infección por el virus de la inmunodeficiencia humana desde los inicios de la pandemia, época en la que se recomendaba su pesquisa sólo en poblaciones de alto riesgo; hasta la actualidad, que se recomienda masivamente.

Describe además la evidencia que respalda estos cambios, las barreras para implementarlos y algunas estrategias que mostraron efectividad para aumentar la proporción de las personas que conocen su status serológico.
\end{abstract}

\section{Abstract}

This article summarizes the historical development of the screening recommendations of human inmunodefficiency virus infection since the beginning of the pandemic period during which its screening was recommended only in high-risk populations; until now, when it is widely recommended.

It describes the evidence supporting these changes and the barriers to implement some strategies that showed effectiveness in increasing the proportion of people who know their HIV status.

Palabras clave: rastreo, virus de la imunodeficiencia humana, promoción. Key words: screening, human inmunodeficiency, promotion.

Burdiso N, Terrasa S, y Kopitowski K. El rastreo de la infección por el virus de la inmunodeficiencia adquirida en individuos asintomáticos sin antecedentes de riesgo. Evid Actual Pract Ambul. 2015;18(3):68-70. Jul-Sep.

\section{Introducción}

Existe en la actualidad evidencia contundente de que el tratamiento de las personas con infección asintomática por el virus de la inmunodeficiencia humana $(\mathrm{VIH})^{+\dagger}$ tiene beneficios individuales y sociales. Por un lado, disminuye la progresión al Síndrome de Inmunodeficiencia Adquirida (SIDA), la incidencia de las enfermedades marcadoras de SIDA y la mortalidad $¥$; y por otro, reduce el riesgo de transmisión sexual y perinatal. Ver tabla 1.

Tabla 1: evidencia que sustenta la eficacia del tratamiento temprano de las personas con infección por el virus de la inunodeficiencia adquirida.

\begin{tabular}{|c|c|c|c|c|}
\hline \multirow[b]{2}{*}{ Autor, lugar y diseño } & \multirow{2}{*}{$\begin{array}{l}\text { Tiempo de } \\
\text { seguimiento }\end{array}$} & \multicolumn{2}{|c|}{ Grupo } & \multirow[b]{2}{*}{ Resultados } \\
\hline & & Intervención & Control & \\
\hline $\begin{array}{l}\text { Cohen y col. }{ }^{1} \\
\text { Nueve países (54\% de África), } 2011 . \\
\text { Ensayo clínico }\end{array}$ & 1,7 años & $\begin{array}{l}\text { Tratamiento con } \\
\text { recuentos de CD4 } \\
\text { entre } 350 \text { y } 550 \\
\quad(n=886)\end{array}$ & $\begin{array}{c}\text { Tratamiento con } \\
\text { recuentos de CD4 } \\
\text { menores } 200 \text { ó síntomas } \\
(n=877)\end{array}$ & $\begin{array}{l}\text { Menor incidencia de eventos clínicos } \\
\text { serios y/o muerte en el grupo } \\
\text { intervención: } 2,4 \text { vs. 4/personas año. } \\
\text { HR 0,59; IC } 95 \% \text { 0,40 a 0,88 }\end{array}$ \\
\hline $\begin{array}{l}\text { Jia Z y col. } \\
\text { China, } 2013 \\
\text { Cohorte retrospectiva }\end{array}$ & 8 años & $\begin{array}{l}\text { Tratamiento con } \\
\text { recuentos de CD4 } \\
\text { entre } 304 \text { y } 509 \\
\quad(n=14805)\end{array}$ & $\begin{array}{l}\text { Tratamiento con } \\
\text { recuentos de CD4 entre } \\
62 \text { a } 269(n=24057)\end{array}$ & $\begin{array}{c}\text { Reducción de la incidencia de infección } \\
\text { de la pareja sero-discordante. } \\
\text { OR } 0,74 ; \text { IC } 95 \% \text { 0,65 a 0,84 } \\
\text { Reducción relativa } 26 \%\end{array}$ \\
\hline $\begin{array}{l}\text { Connor E y col. }{ }^{3} \\
\text { EE.UU. y Francia, } 1994 \\
\text { Ensayo clínico. }\end{array}$ & 2,6 años & $\begin{array}{l}\text { Zidovudina }(Z d v) \\
\text { desde la semana } \\
\text { 28, intraparto, y al } \\
\text { bebe hasta las } 6 \\
\text { semanas. } \\
(n=180)\end{array}$ & $\begin{array}{l}\text { Placebo } \\
(n=183)\end{array}$ & $\begin{array}{c}\text { Grupo Zdv } 13 \text { infectados }(8,3 \% ; \text { IC } 95 \% \\
3,9 \text { a } 12,8) \\
\text { Grupo control } 40 \text { infectados }(25,5 \% \\
18.4 \text { a } 32,5) \\
\text { RR } 67,5 \%(40,7 \text { a } 82,1)\end{array}$ \\
\hline
\end{tabular}

${ }^{\dagger \dagger}$ Las personas asintomáticas suelen tener un recuento de linfocitos CD4 entre 200 y 500 células $/ \mathrm{mL}$.

\#¥ Si bien el tratamiento de las personas con infección por VIH implica una mayor probabilidad de desarrollar efectos adversos en el corto plazo, estos suelen auto limitarse. Por otro, la mayor incidencia de enfermedad cardiovascular se ve compensada con creces con la reducción la morbi-mortalidad asociada a la infección por VIH. 


\section{Recomendaciones de rastreo de la infección por el virus de} la inmunodeficiencia adquirida

Desde los comienzos de la pandemia, la recomendación de la pesquisa individual de $\mathrm{VIH}$ estaba dirigida a las personas con antecedentes de conductas de riesgo de contagio, ante síntomas compatibles con infección aguda por VIH o síndrome de la inmunodeficiencia adquirida (SIDA), y previamente a la donación sangre o hemoderivados, debido a que los riesgos del rastreo masivo implementado a nivel poblacional (alta probabilidad de resultados falsamente positivos, estigmatización, etc.) parecían superar sus potenciales beneficios.

Sin embargo, la difusión de los beneficios de la terapia antiretroviral (en inglés ART) y del rastreo rutinario en determinadas situaciones y poblaciones (en bancos de sangre, durante el control prenatal) motivó un cambio de enfoque respecto de las estrategias preventivas y de diagnóstico precoz de esta infección. A partir de 2006, tanto el Centro de Control de Enfermedades de EE.UU (en inglés CDC) como la Organización Mundial de la Salud (OMS) y otras organizaciones $^{4,5,6}$ comenzaron a recomendar el rastreo en forma rutinaria a todos los adolescentes y adultos de las poblaciones cuya prevalencia de infección por VIH superara el $0,1 \%$; siempre respetando la voluntad del individuo a ser pesquisado $\$$. En abril de 2013, se publicaron las nuevas recomendaciones de la Fuerza de Tareas de Servicios Preventivos de EE.UU. (en inglés U.S Preventive Service Task and Force: USPSTF) sobre el rastreo de $\mathrm{VIH}$, que recomiendan: 1) la pesquisa de toda persona de 15 a 65 años y embarazadas de cualquier edad, independientemente de que se constaten antecedentes de conductas de riesgo; 2) la evaluación del riesgo individual para definir la necesidad de un segundo test y el intervalo inter-prueba ${ }^{7}$.

En el mismo año, la Dirección de SIDA y enfermedades de transmisión sexual (ETS) del Ministerio de Salud de la Nación Argentina publicó las recomendaciones para ofrecer la prueba de VIH con asesoramiento pre y pos test, con el fin de brindar las herramientas para el proceso de asesoramiento, en especial a los centros de atención primaria, y de esta forma aumentar el acceso a la prueba de VIH. Estas recomendaciones sugieren ofrecer la prueba realizando asesoramiento pre test y post test ${ }^{\star * \star}$ a todos los grupos poblacionales, pero enfatiza en algunos grupos especiales de mayor riesgo de infección ${ }^{\text {tt+8 }}$.

\section{Las dificultades para la implementación del rastreo}

A pesar de las recomendaciones del CDC y la USPSTF (que fueron avalados por otras Instituciones de Salud) para el rastreo rutinario, los datos obtenidos del seguimiento de la pandemia en distintos países evidencian que un grupo importante de la población infectada no conoce su estado de portador, lo que aumenta la probabilidad de que se le haga el diagnóstico en forma tardía ${ }^{\ddagger \neq}$. El hecho de que las personas infectadas no conozcan su estado de portador aumenta la probabilidad de que transmitan la infección. Por otro lado, las personas a quienes se les realiza un diagnóstico tardío se ven privadas de la posibilidad de un inicio temprano de la terapia antirretroviral.
Barreras para la implementación de la pesquisa de la infección por el virus de la inmunodeficiencia adquirida en población asintomática

A pesar que la evidencia internacional sostiene que existe alta aceptación en la población respecto de realizar pesquisa de $\mathrm{VIH}$, existe evidencia de que los profesionales de la salud no ofrecen el test de VIH en forma rutinaria ${ }^{9}$.

Cabana y col..$^{10}$ describieron un modelo que intenta explicar la falta de adherencia en la implementación de las recomendaciones de Guías de Práctica Clínicas: 1) falta de conocimiento de la recomendación, 2) falta de actitud para implementarla por diversos motivos (desacuerdo con la recomendación o escepticismo respecto de su resultado, inercia clínica/falta de autoeficacia para cambiar de conducta), 3) barreras externas (falta de tiempo o reconocimiento económico del tiempo destinado a la consejería y/o en la implementación de la firma del consentimiento, miedo al estigma) ${ }^{11}$, etc. Cada una de las cuales permiten explicar la falta de adherencia de los médicos a la recomendación del testeo universal del $\mathrm{VIH} .{ }^{12}$

\section{Estrategias que han sido implementadas para incrementar} la tasa de rastreo del virus de la inmunodeficiencia humana

En pos de incrementar la tasa de solicitud del test de VIH tanto a los grupos en riesgo como a la población en general, se han implementado múltiples estrategias, algunas de ellas destinadas a los profesionales de la salud y otras, a la población general.

\section{Estrategias destinadas a profesionales de la salud}

Entre las estrategias destinadas a los profesionales de la salud con documentada eficacia para incrementar las tasas de rastreo de $\mathrm{VIH}$ se destacan las intervenciones multimodales que se han desarrollado en el contexto de programas de mejoría de la calidad de atención clínica ${ }^{\S \S}$, aplicadas al abordaje de la problemática del $\mathrm{VIH}^{13,14}$.

Las intervenciones multimodales incluyen las estrategias ${ }^{* * *}$ que se describen en el cuadro 1.

Cuadro 1: intervenciones multimodales para promover el rastreo de la infección por el virus de la inmunodeficiencia humana.

- Recordatorios electrónicos en tiempo real de que el paciente no ha sido pesquisado

- Comunicación periódica con los profesionales de la salud respecto de la proporción de su población a cargo que conoce su status serológico o que ha realizado la prueba.

- Intervenciones motivacionales a los profesionales de la salud (intervenciones individuales, colectivas través de líderes de opinión, difusión de material educativo, etc.)

- Procesos de optimización del tiempo necesario para la consejería pre y post test involucrando diferentes actores del equipo de salud (p. ej. enfermeros, promotores de salud, agentes sanitarios), usando formularios estructurados para realizar consentimiento informado y notificando telefónicamente los resultados negativos.

\footnotetext{
${ }^{\$ \$}$ Las recomendaciones de estas organizaciones es el rastreo opt-out del HIV, que significa realizar la prueba de VIH de rutina a menos que el paciente rechace ser testeado explícitamente, y eliminan la necesidad del consentimiento informado, de la asesoría pre test, y de la consejería pos test. A menos que las leyes de las jurisdicción no sean consistentes con este enfoque.

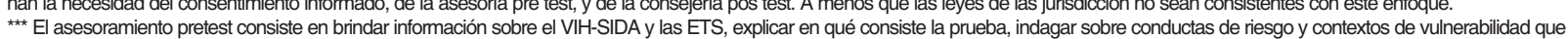
alteren la capacidad de dar respuesta a la infección, ofrecer la prueba de SIFILIS, dar información sobre el consentimiento informado, solicitar la firma del consentimiento informado. El asesoramiento post test consiste en realizar un asesoramiento post test que implica dar el resultado, asegurarse la comprensión del mismo, entregar información de formas de prevención sin importar el resultado, dirigir a centros de asistencia específicos en caso de un resultado positivo.

"t+Mujeres embarazadas, hombres heterosexuales, parejas de personas con la infección, personas que desean hacerse la prueba, aquellas con diagnóstico de alguna infección de transmisión sexual y sus parejas, trabajadores sexuales, usuarios de drogas, personas frente alguna situación de riesgo.

\# Se denomina diagnóstico tardío de la infección por VIH a su detección al momento de presentar una enfermedad marcadora, o aparición de esta antes de los 12 meses de realizado el diagnostico de infección por HIV.
} 
Estrategias destinadas a la población general

Entre las destinadas a la población general, distintos estudios han documentado que los métodos de difusión social son eficaces en la promoción del rastreo de la infección por VIH . Por otro lado, el acceso a la consejería y al testeo voluntario en poblaciones con escasa accesibilidad geográfica a los servicios de salud, puede aumentarse mediante la implementación de dispositivos móviles que la brindan en puntos cercanos a donde viven estas poblaciones ${ }^{15}$.

\section{La situación en Argentina}

Datos locales de 2010 a 2012 permiten estimar que viven en Argentina alrededor de 110 mil personas con $\mathrm{VIH}$ y que el $30 \%$ no conoce su situación; que se continúan infectando alrededor de 5.000 personas cada año (100 de ellas por transmisión vertical) y que fallecen 1.400 personas por SIDA en ese mismo lapso. Las mismas fuentes documentan que en Argentina 15\% de las mujeres y $26 \%$ de los varones reciben el diagnóstico tardíamente, proporción que se mantiene estable desde hace 10 años .
En el contexto de los cambios ocurridos en los últimos años que acabamos de describir, la dirección de SIDA y ETS del Ministerio de Salud de la Nación elaboró el Plan Estratégico Nacional (PEN) 2013-2017, con el apoyo del Programa Conjunto de las Naciones Unidas para el SIDA (ONUSIDA), cuyo objetivo es detener y revertir la epidemia del $\mathrm{VIH}$ y otras infecciones de transmisión sexual (ITS). Este plan se presentó el primero de diciembre (Día Mundial del SIDA) del 2013 junto a la campaña "Elegir Saber" para promover el testeo de VIH en la Argentina. ${ }^{16}$

Una de las metas de la dirección de SIDA y ETS es mejorar la accesibilidad al diagnóstico del VIH y otras ITS, para ello trabaja en dos líneas complementarias: la estimulación de la demanda espontánea del diagnóstico promoviendo el testeo voluntario con asesoramiento; y la promoción de la oferta activa del estudio en el marco de la consulta médica.

Recibido el 20/08/2015 y aceptado el 30/09/2015

\section{Referencias}

1. Cohen MS, y col. HPTN 052 Study Team. Prevention of HIV-1 infection with early antiretroviral therapy. N EnglJ Med. 2011;365:493-505. [PMID:21767103]

2. Jia Z, y col. Antiretroviral therapy to prevent HIV transmission in serodiscordant couples in China (2003-11): a national observational cohort study. Lancet.2013;382(9899):1195-1203. doi: 10.1016/S0140-6736(12)61898-4.

3. Connor EM y col. Reduction of maternal-infant transmission of human immunodeficiency virus type 1 with zidovudine treatment. Pediatric AIDS Clinical Trials Group Protocol 076 Study Group.NEngl J Med. 1994 Nov 3;331(18):1173-80.

4. American College of Obstetricians and Gynecologists. ACOG committee opinion: routine human immunodeficiency virus screening. Obstet Gynecol. 2008 ; 112(2 pt 1):401-403. [PubMed:18669743]

5. Emmanuel PJ, y col. Adolescent and HIV infection: the pediatrician's role in promoting routine testing. Pediatrics. 2011; 128(5):1023-1029. [PubMed: 22042816]

6. Qaseem A, y col. Clinical Efficacy Assessment Subcommittee, American College of Physicians. Screening for HIV in health care settings: a guidance statement from the American college of physicians and HIV medicine association. Ann InternMed. 2009; 150(2):125-131. [PubMed: 19047022]

7. Moyer VA. on behalf of the U S. Preventive services task force. screening for HIV: U.S. preventive services task force recommendation statement. Ann InternMed. 2013; 159(1):51-60. [PubMed:23698354]

8. Dirección de SIDA y ETS, Ministerio de Salud de la Nación. Diagnostico VIH-Recomendaciones para el asesoramiento pre y post test. 2013. http://www.msal.gov.ar/images/stories/bes/graficos/0000000117cnt-2013-05_guia-diagnostico-asesoramiento-2013.pd

9. Elmahdi R,y col. Low levels of HIV test coverage in clinical settings in the UK: a systematic review of adherence to 2008 guidelines. Sex Transm Infect 2014;90:119-124.

10. Cabana MD, y col. Why don't physicians follow clinical practice guidelines? a framework for improvement. JAMA. 1999;282(15):1458-1465

11. Bokhour BG, y col. Barriers and facilitators to routine HIV testing in VA primary care. J Gen InternMed. 2009;24(10):1109-1114.

12. Micha Yin Zheng, y col. Physician Barriers to Successful Implementation of US Preventive Services Task Force Routine HIV Testing Recommendations. J Int Assoc Provid AIDS Care. 2014 May; 13(3): 200-205.

13. Goetz MB, Hoang T, BowmanC, etal. A system-wide intervention to improve HIV testing in the Veterans Health Administration. J Gen Intern -Med.2008;23:12007.

14. Goetz MB, Bowman C, Hoang T, et al. Implementing and evaluating a regional strategy to improve testing rates in VA patients at risk for HIV, utilizing the QUERI process as a guiding framework: QUERI Series. Implement Sci. 2008:3:16

15. Kawamoto K, Houlihan CA, Balas EA, Lobach DF. Improving clinical practice using clinical decision support systems: a systematic review of trials to identify features critical to success. BMJ. 2005;330:765

16. Dirección de SIDA y ETS. Ministerio de Salud de la Nación Argentina. Boletín sobre VIH-SIDA e ITS en la Argentina. 2013

${ }^{55}$ Las Programa QUERI (Quality Enhancement Research Initiative), programa cuyo objetivo es mejorar la atención médica a los pacientes mediante la aplicación de la evidencia en la práctica clínica. Evalúa los impactos intencionales y no intencionales de nuevos tratamientos o recomendaciones, y aplica estrategias para acelerar la adopción de la nueva evidencia en la práctica clínica.

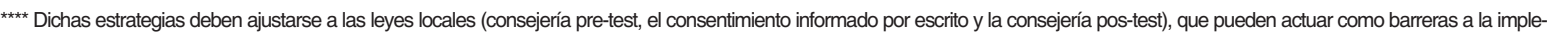
mentación del rastreo de $\mathrm{VIH}$. 